University of Nebraska - Lincoln

DigitalCommons@University of Nebraska - Lincoln

\title{
Contest behaviour of maize weevil larvae when competing within seeds
}

Nelsa Maria P. Guedes

Universidade Federal de Vicosa

Raul Narciso C. Guedes

Universidade Federal de Vicosa, guedes@ufv.br

James F. Campbell

USDA-ARS, james.campbell@usda.gov

James E. Throne

USDA-ARS, Manhattan, KS, james.throne@ars.usda.gov

Follow this and additional works at: https://digitalcommons.unl.edu/usdaarsfacpub

Guedes, Nelsa Maria P.; Guedes, Raul Narciso C.; Campbell, James F.; and Throne, James E., "Contest behaviour of maize weevil larvae when competing within seeds" (2010). Publications from USDA-ARS / UNL Faculty. 1978.

https://digitalcommons.unl.edu/usdaarsfacpub/1978

This Article is brought to you for free and open access by the U.S. Department of Agriculture: Agricultural Research Service, Lincoln, Nebraska at DigitalCommons@University of Nebraska - Lincoln. It has been accepted for inclusion in Publications from USDA-ARS / UNL Faculty by an authorized administrator of DigitalCommons@University of Nebraska - Lincoln. 


\title{
Contest behaviour of maize weevil larvae when competing within seeds
}

\author{
Nelsa Maria P. Guedes ${ }^{\text {a,b }}$, Raul Narciso C. Guedes ${ }^{\text {a,b,* }}$, James F. Campbell ${ }^{\text {b, }}$, James E. Throne ${ }^{\text {b, } 1}$ \\ a Departamento de Biologia Animal, Universidade Federal de Viçosa \\ ${ }^{\mathrm{b}}$ USDA-ARS Grain Marketing and Production Research Center, Manhattan, Kansas
}

\section{A R T I C L E I N F O}

\section{Article history:}

Received 23 June 2009

Initial acceptance 22 July 2009

Final acceptance 1 October 2009

Available online 14 December 2009

MS. number: A09-00418R1

\section{Keywords:}

competition strategy

Curculionidae

interaction

intraspecific competition

life-history trait

maize weevil

resource monopolization

scramble competition

Sitophilus zeamais

Zea mays

\begin{abstract}
Food limitation induces severe competition for obligate seed-feeding insect larvae that are unable to leave the seed selected by their mother. The number of eggs laid per seed and the number of larvae hatched from the eggs are important determinants of whether larval behaviour within the seed will be of the scramble or the contest type. In maize weevils, Sitophilus zeamais, few adults emerge per seed regardless of the number of eggs laid, which may arise from scramble competition, if the optimum egg density (i.e. egg density leading to maximum total larval fitness) is low compared to the number of eggs laid per seed, or from contest competition due to direct interference among the larvae. The behavioural process and the ecological outcome of competition were assessed in two strains of the maize weevil. Neither strain showed a reduction in body mass with increased competition, and they had similar optimal egg densities (two eggs per seed). There was a hump in the larval fitness curve suggesting a scramble competition, but this conclusion is compromised because the optimum egg density was small (two eggs per seed). X-ray imaging of seeds was used to observe interactions of larvae within the seed and showed direct interference, with aggression among the larvae. This provides evidence of contest-like competition within seeds even when egg density was low. Hence, one should be cautious in inferring the underlying type of competitive behaviour from variables such as body mass and initial egg density per seed. Direct observation of behaviour is required to make such an inference.
\end{abstract}

(c) 2009 The Association for the Study of Animal Behaviour. Published by Elsevier Ltd. All rights reserved.
Local resource competition may lead to the selection of specific adaptive behaviour to overcome harmful interference among individuals (Sanz \& Gurrea 2000; Alves-Costa \& Knogge 2005), and this may have consequences for life-history traits (Smith \& Lessells 1985; Smith 1990, 1991). Nicholson (1954) originally defined two distinct strategies of intraspecific competition, scramble and contest, which are frequently recognized in terms of resource use (e.g. Varley et al. 1973; Lomnicki 1988). In scramble competition, all members of a population have equal access to a limited resource, whereas under contest competition some members of a population (the winners) secure the available resource for their survival and reproduction, unlike others (the losers), who die.

The resource-limitation concept of competition is populationbased. However, Nicholson (1954) also recognized the process by which competition takes place (i.e. its behavioural mechanism). The process of scramble competition takes place when there is accommodation of all competitors within a resource patch. The

\footnotetext{
* Correspondence: R. N. C. Guedes, Departamento de Biologia Animal, Universidade Federal de Viçosa, Viçosa, MG 36571-000, Brazil.

E-mail address: guedes@ufv.br (R.N.C. Guedes).

1 J. F. Campbell and J. E. Throne are at the USDA-ARS Grain Marketing and Production Research Center, Manhattan, KS 66502, U.S.A.
}

scramble process allows increased survival, but with reduced individual resource gain and consequently lower body mass gain with development, unlike in contest competition (Bakker 1961; Miller 1967; De Jong 1976; Giga \& Smith 1991; Toquenaga 1993; Jansen \& Sevenster 1997; Lale \& Vidal 2001; Guedes et al. 2007). Contest competition implies direct interference among competitors (i.e. behavioural interference, such as aggressive attack) and typically only a single winner per territory (De Jong 1976; Smith \& Lessells 1985; Guedes et al. 2007; Mano et al. 2007). The proximate behaviour underlying competition is, however, poorly studied, particularly for seed beetles (Guedes et al. 2003, 2007; Alves-Costa \& Knogge 2005). This is because competition strategies are usually inferred from their final outcome: the relationship of the number (or fitness) of surviving individuals to the initial number entering the limited resource (Varley et al. 1973; Bellows 1982; Guedes et al. 2003).

There have been proximal studies of larval competition with the cowpea weevil, Callosobruchus maculatus (F.) (Coleoptera: Bruchidae), in which contest competition prevails in small host seeds (Messina 1991, 2004). Preliminary investigation of a 'contest' strain of $C$. maculatus indicated that vibrations are likely to mediate the process of competition, leading the dominant larva delaying the development of the conspecifics (Thanthianga \& Mitchell 1987), although no playback studies were carried out to confirm this 
hypothesis. High feeding and respiration rates were also associated with contest competition in another strain of $C$. maculatus collected in lentils (Credland \& Dick 1987; Daniel \& Smith 1994; Guedes et al. 2003). In contrast, recent recognition of wall-making behaviour associated with 'scramble' strains of $C$. maculatus indicates that such behaviour may minimize direct interference among larvae, favouring similar resource partitioning among them and consequently leading to a scramble outcome of competition (Mano \& Toquenaga 2008a, b).

The distinction between the behavioural process of competition and the ecological outcome after competition is essential (Smith \& Lessells 1985; Smith 1990; Guedes et al. 2007). Although the process of competition results from intrinsically disruptive selection, the outcome also depends on the amount of resource required for development relative to its availability (Smith \& Lessells 1985). A contest outcome may result even from a scramble process (i.e. without behavioural interference) depending on the resource availability and proximal mechanism involved, with consequences on life-history evolution (Smith 1990; Colegrave 1994, 1997; Nylin 2001; Guedes et al. 2003, 2007). For example, the large larvae with high metabolic rate from some strains of $C$. maculatus present a contest-like outcome of competition despite showing a scramble process of competition (Credland et al. 1986; Daniel \& Smith 1994; Guedes et al. 2003).

Intensive selection is to be expected when resource units are discrete. This is the case for seeds parasitized by seed beetles that spend their larval stages within a single seed selected by their mother. Thus, the seed is a closed system within which the young larvae are unable to avoid competition with each other when multiple eggs are laid per seed (Smith 1990, 1991; Colegrave 1994). Seed beetles, such as the maize weevil, Sitophilus zeamais Motschulsky (Coleoptera: Curculionidae), can lay multiple eggs in a seed, thus increasing competition among the larvae within the seed (Smith \& Lessells 1985; Danho et al. 2002; Danho \& Haubruge 2003a). Females of this species tend to cluster their eggs in a few seeds subjected to multiple visits, which may also be the target of further egg-laying by other females (Smith \& Lessells 1985; Danho \& Haubruge 2003a, b), as was also reported for the related species Sitophilus granarius, the granary weevil (Fava \& Burlando 1995). Clustered egg distributions of the maize weevil may be less common in the natural environment because fewer than two eggs per seed is usually observed, in contrast with laboratory studies (Throne 1994; Danho et al. 2002; Danho \& Haubruge 2003a).

The maize weevil is an insect pest of cereals throughout agricultural regions of the world. There are large strain differences, most likely resulting from the way they are managed as pests (e.g. insecticide resistance; Fragoso et al. 2003, 2005; Guedes et al. 2006; Araújo et al. 2008; Guedes et al. 2009a). These strain differences may also arise because of the discontinuous nature of the stored seed environment. This probably accentuates seasonal population cycles. Such cycles lead to bottlenecks in population size, so that only small numbers of individuals establish new populations
(Tanaka 1990; Tran \& Credland 1995; Guedes et al. 1997). Few individuals emerge from seeds infested by more than one larva of this species (Throne 1994; Danho et al. 2002; Danho \& Haubruge 2003a). The low rate of adult emergence in the maize weevil may result either from a scramble process, with a low (optimum) egg density leading to a peak in larval fitness, or from a contest process of competition with direct interference among the larvae. Both processes may generate a scramble outcome with an optimum egg density (i.e. egg density leading to maximum total larval fitness), but scramble competition reduces individual resources, again leading to lower adult body mass at emergence, unlike contest competition (Bakker 1961; De Jong 1976; Giga \& Smith 1991; Jansen \& Sevenster 1997; Guedes et al. 2007). The behavioural process and the ecological outcome of competition were assessed in two strains of the maize weevil. One of the strains is resistant to insecticides, but with no fitness disadvantage associated with this trait, probably because of its higher food consumption and higher energy metabolism (Guedes et al. 2006; Araújo et al. 2008; Guedes et al. 2009b), which may impact its competitive ability as reported in C. maculatus (Credland \& Dick 1987; Daniel \& Smith 1994; Guedes et al. 2003).

The main objective of this study was to determine the ecological outcome and underlying behavioural process of larval competition in strains of a seed beetle, which are seldom considered simultaneously. Sequential X-ray images were used to characterize the larval interactions taking place within the seed and how they relate to quantitative determinations obtained in this investigation and commonly used (indirectly) to recognize the behavioural process of competition involved (Table 1). Existence of competition is recognized by the decrease in percentage of adults emerging as egg density in the parasitized seed increases, which was expected in the maize weevil regardless of the outcome and behavioural process involved. The competition outcome is recognized by the shape of the larval fitness curve (i.e. insect biomass produced per seed) as a function of egg density: a peak indicates scramble competition, whereas a plateau reached at high egg densities indicates contest competition. The contest outcome of competition can be achieved either through a contest type of behavioural process with direct interference between larvae or through high larval feeding and metabolic rates leading to quick resource depletion and high larval mortality (low adult emergence). The scramble outcome may also be achieved through either a scramble process (e.g. accommodation via wall-making behaviour isolating the individual larva) or a contest-behavioural process.

The contest-behavioural process of competition implies direct interference among larvae favouring the dominant larva, but impairing the development of the others, which is more likely to take place when the insects show higher food consumption and therefore, higher metabolism (determined as respiration rate) and weight gain. Such direct interference or encounter among larvae may result in active aggression and even cannibalism, but evidence for these in seed beetles is lacking. The low rate of adult emergence

Table 1

Quantitative predictions as a function of egg density used (indirectly) to recognize the behavioural process and ecological outcome of competition

\begin{tabular}{|c|c|c|c|c|}
\hline \multirow[t]{3}{*}{ Trait } & \multicolumn{4}{|l|}{ Competition outcome } \\
\hline & \multicolumn{2}{|l|}{ Scramble } & \multicolumn{2}{|l|}{ Contest } \\
\hline & Scramble process & Contest process & Scramble process & Contest process \\
\hline Relative adult emergence per seed (\%) & Decrease & Decrease & Decrease & Decrease \\
\hline Absolute adult emergence per seed & Decrease & Decrease & Decrease & Does not vary \\
\hline Larval competition curves & Peak & Peak (at low densities) & Plateau (at high densities) & Plateau (at high density) \\
\hline Body mass & Decrease & Does not vary & Decrease & Does not vary \\
\hline Respiration rate & $\begin{array}{l}\text { Lower regardless of egg } \\
\text { density }\end{array}$ & $\begin{array}{l}\text { Higher regardless of egg } \\
\text { density }\end{array}$ & $\begin{array}{l}\text { Higher regardless of egg } \\
\text { density }\end{array}$ & $\begin{array}{l}\text { Higher regardless of egg } \\
\text { density }\end{array}$ \\
\hline
\end{tabular}


per parasitized seed reported for the maize weevil is suggestive of a contest outcome of competition resulting from a contest-behavioural process with increasing rate of larvae interference (i.e. encounter) with egg density and possibly aggression among larvae. Such an expected result would be even clearer in the insecticideresistant strain of maize weevil because it shows higher food consumption and respiration rates (as well as body mass) than the insecticide-susceptible strain, increasing the probability of larval encounters within the seed, which is the reasoning for including both strains in the study and determining respiration rates.

\section{METHODS}

\section{Insect Populations}

Two strains of S. zeamais were used, one susceptible and one resistant to insecticides (Guedes et al. 1994; Ribeiro et al. 2003). The susceptible strain was collected in the mid-1980s in Sete Lagoas County (state of Minas Gerais, Brazil). The resistant strain was collected in Jacarezinho County (state of Paraná, Brazil) in the late 1980s (Guedes et al. 1994, 1995). It is resistant to pyrethroid insecticides, but does not suffer a fitness cost associated with insecticide resistance (Fragoso et al. 2005; Oliveira et al. 2007). Both strains were derived from stock cultures maintained at the Maize and Sorghum Research Centre of the Brazilian Agricultural Research Corporation (EMBRAPA Milho \& Sorghum, Sete Lagoas, MG, Brazil). The insect cultures were maintained in whole maize grains (13\% m.c.) free of insecticides using the same procedures and densities in environmentally controlled conditions of temperature $\left(28 \pm 2{ }^{\circ} \mathrm{C}\right)$, relative humidity $(70 \pm 5 \%)$, and photoperiod (light: dark 12:12 h).

\section{Competition Experiments}

Maize seeds with various infestation densities were randomly obtained by the following procedure. First, 25 pairs of 5-day-old adults from each strain were allowed to mate for $24 \mathrm{~h}$. After the males were removed, all 25 females were allowed to lay eggs for $24 \mathrm{~h}$ in a new batch of 20 seeds, which were standardized by size by using kernels that passed through a sieve with $6.35 \mathrm{~mm}$ openings but were retained on a no. 6 sieve. The seeds were then examined under a dissecting microscope for the presence of eggs. In this way, the initial egg density was determined. Egg densities ranged from one to seven eggs per seed. These egg-density assessments were checked by digital X-ray imaging, as described below. The number of replicates (i.e. seeds) per egg density and strain was inversely proportional to the egg density, ranging from 3 to 24 because of the difficulty in obtaining seeds with highest egg densities. The larvae sharing a seed are confounded by a common seed environment, and eggs from intermediate densities were likely to be from the same female (because they tend to cluster their eggs and lay them in low densities), unlike those at high egg densities. Therefore, the larvae sharing a seed were regarded as pseudo-replicates and only average results from different seeds were considered replicates. The seeds were maintained separately under controlled conditions until the onset of adult emergence. From then on, observations were made daily and the emergence, sex, body mass, and developmental time were recorded for each individual on the day of emergence (Giga \& Smith 1991; Guedes et al. 2007). The emerged adults were sexed using rostrum patterns of shape and texture (Reddy 1951; Tolpo \& Morrison 1965) and individually weighed on a UMT2 microbalance (Mettler Toledo, Columbus, OH, U.S.A.). All of the maize seeds containing eggs were observed every other day (and daily upon imminence of larval interaction) using an MX-20 specimen radiography system equipped with a 14-bit digital camera (Faxitron X-Ray Corp., Wheeling, IL, U.S.A.). The locations and interactions among larvae within the seeds were digitally recorded throughout their development. An interaction, or encounter, was defined as two insects encountering each other within a kernel. Possible outcomes of an encounter were the insects moving away from each other or one of the insects being killed.

\section{Respirometry}

Carbon dioxide production was measured in a Micro-Oxymax 10-channel computerized respirometer with dual-range $\mathrm{O}_{2}$ and $\mathrm{CO}_{2}$ detectors (Micro-Oxymax; Columbus Instruments, Columbus, $\mathrm{OH}$, U.S.A.). A series of $50 \mathrm{ml}$ flasks was used, each flask randomly containing a single maize seed with a single hatched larva (15 days old) in its interior, as verified by X-ray imaging. The respiration rate ( $\mu \mathrm{l} \mathrm{CO}_{2}$ produced/h/larva) was determined for $24 \mathrm{~h}$ in 20 insects of each strain in addition to a control treatment in which the respiration rate of only the maize seed without any eggs was determined to correct the values obtained for each strain against seed respiration. After the measurement, the seeds were removed from the flasks and randomly placed in individual wells of 24-well insecttissue-culture plates provided with lids. After adult emergence, their body mass was determined. The respiration rate was assessed because it is an indication of larval metabolic rate and food consumption, which may favour a contest-type outcome when at higher levels in one of the strains, as observed with the Yemen strain of the cowpea weevil (Daniel \& Smith 1994; Guedes et al. 2003). More particularly, the higher respiration rate may reflect higher rates of seed consumption or development, increasing the rate of larval mutual interference within the seed. In this study, the insecticide-resistant strain of maize weevils showed a higher energy metabolism and higher respiration rate, which potentially compensates for fitness costs usually associated with insecticide resistance (Guedes et al. 2006; Araújo et al. 2008) and may be related to the behavioural process of larval competition within the seed making such determination of respiration necessary. Although respiration rates for these strains were determined previously (Guedes et al. 2006), those rates were for groups of adult insects, and here we determined respiration rates for individual larvae.

\section{Data Analyses}

Adult emergence data were subjected to regression analysis $(P<0.05)$ using TableCurve 2D (SPSS 2000) by fitting percentage adult emergence $(y)$ against egg density $(x)$ using a model derived from Horn (1997), following Guedes et al. (2007): $y=\alpha x^{-\beta}$, where $\alpha$ is a measure of the quality of the host for the seed beetle (i.e. the adult emergence from a seed with a single egg), and $\beta$ is the competition coefficient (the higher $\beta$ is, the higher the competition is). Adult body mass, developmental time, proportion of females (no. females/total no. insects), and interactions among larvae within the seed (no. encounters/seed, until adult emergence) were subjected to analysis of covariance $(P<0.05)$. Insect strain was the independent variable and the density of eggs was the covariate for the analysis of covariance of proportion of females emerged and of the interaction between larvae within the seed (PROC GLM; SAS Institute 2002). In contrast, sex and insect strain were the independent variables and the density of eggs was the covariate for the analysis of covariance of adult body mass and developmental time (PROC GLM; SAS Institute 2002). Complementary regression analyses $(P<0.05)$ were carried out for each strain when necessary to recognize the quantitative relationship present (PROC REG; SAS Institute 2002).

Fecundity and longevity are both related to body mass and larval survival, and adult body mass at emergence is affected by 
competition (Anderson 1978; Smith \& Lessells 1985). Therefore, these parameters should all be included in measures of fitness, which was achieved in this work by estimating the insect biomass (mg) produced per seed, used as a measure of total larval fitness to generate larval competition curves (Smith \& Lessells 1985; Guedes et al. 2007). The use of insect biomass as a fitness proxy has been consistently used for seed beetles (e.g. Smith \& Lessells 1985; Smith 1990; Danho \& Haubruge 2003b; Guedes et al. 2003, 2007), but not always for other organisms such as parasitoid wasps (Kazmer \& Luck 1995; Ellers et al. 1998). The significant regression models $(P<0.05)$ were tested from the simplest (linear and quadratic) to alternative models of increasing complexity (nonlinear peak models). TableCurve 2D was used to fit these curves (SPSS 2000). Model selection was based on parsimony, high $F$ values (and mean squares), and steep increase in $R^{2}$ with model complexity. Residual distribution was also checked for each analysis in TableCurve 2D to validate parametric assumptions.

\section{RESULTS}

\section{Adult Emergence}

The adult emergence curves for the two insect strains were indistinguishable $(\alpha=64.48 \pm 4.99$ and $71.79 \pm 3.85$ and $\beta=0.97 \pm 0.11$ and $0.92 \pm 0.08$ for the susceptible and resistant strains, respectively, using $y=\alpha x^{-\beta}$ as a model), and therefore their data were pooled for a single estimated curve of adult emergence (Fig. 1). The higher the density of eggs laid per seed, the lower was the relative adult emergence (i.e. per cent). Host quality $(\alpha=68.20 \pm 3.31 \%)$ and intensity of competition $(\beta=0.95 \pm 0.07)$ were both high. In contrast, there was no significant variation $(P>0.05)$ in absolute adult emergence (i.e. no. adults emerged per seed) with egg density, with $0.69 \pm 0.05$ adults emerged per seed across all densities.

\section{Body Mass, Developmental Time, and Proportion of Females}

Analysis of covariance for adult body mass, developmental time, and proportion of females indicated significant differences only for body mass $\left(F_{21,101}=7.2 ; P<0.001\right)$. There was no significant effect $(P>0.05)$ of strain, egg density, or their interaction on proportion

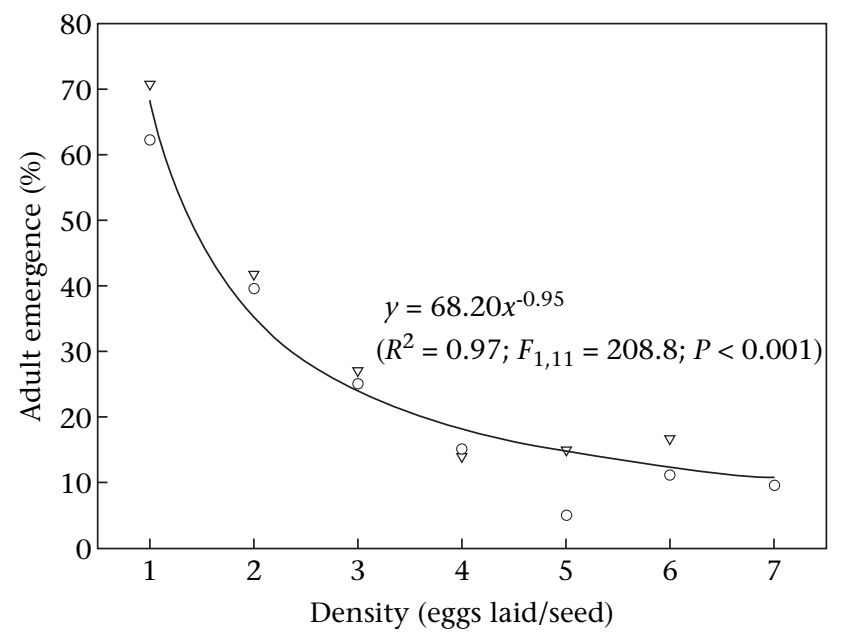

Figure 1. Adult emergence (\%) of two strains of S. zeamais, one susceptible and one resistant to insecticides, subjected to increasing density of eggs on maize seeds (and therefore increasing levels of larval competition). Each symbol represents the observed results for each strain, which were pooled together to fit the exponential model $y=\alpha x^{-\beta}$. ०: Susceptible; $\nabla$ : resistant. of females $(0.61 \pm 0.08)$, nor was there an effect of strain, sex, egg density, or their interactions on developmental time $(39.56 \pm 0.56$ days). Sex and egg density (and their interaction) did not affect adult body mass at emergence $(P>0.05)$, but there was significant effect of strain on adult body mass at emergence $\left(F_{1,101}=29.3\right.$; $P<0.001)$, with insects from the resistant strain showing significantly higher body mass $(3.61 \pm 0.06 \mathrm{mg})$ than those from the susceptible strain $(2.80 \pm 0.05 \mathrm{mg})$.

\section{Larval Competition Curves}

The competition curves relate total larval fitness (as adult biomass produced per seed) to density of eggs laid (Fig. 2). The best model obtained for both strains indicates a peak for both strains at the same egg density, two eggs per seed (Fig. 2), despite the resistant strain showing significantly higher larval fitness than the susceptible strain.

\section{Larval Respiration Rates}

The higher body mass and larval fitness of the resistant strain indicated that a higher respiration rate was expected. The two-way analysis of variance (strain $\times$ sex) for respiration rate indicated significant differences for strain only $\left(F_{1,65}=3.7 ; P=0.016\right)$, with the larvae of the resistant strain showing significantly higher respiration rate $\left(21.41 \pm 1.57 \mu \mathrm{lCO}_{2} /\right.$ insect/h$)$ than the larvae of the susceptible strain $\left(16.13 \pm 1.99 \mu \mathrm{l} \mathrm{CO}_{2} /\right.$ insect/h). However, because the same model described the hump-shaped curve of total larval fitness for both strains, the difference in respiration rate between the strains does not seem to play any role in the outcome of competition among maize weevil larvae.

\section{$X$-Ray Imaging}

Adult body mass at emergence is commonly used to infer indirectly the underlying type of competition within seeds (Smith \&

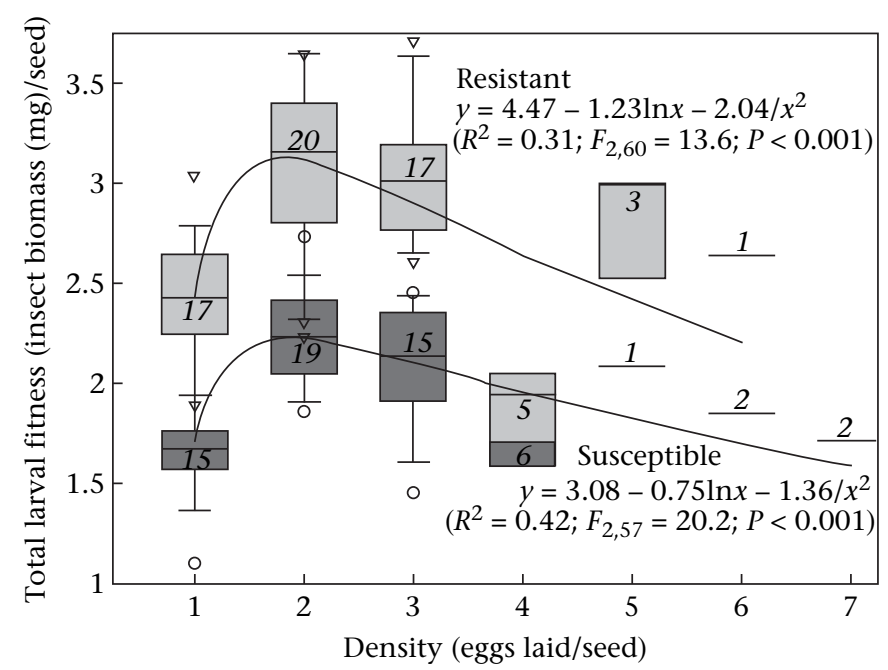

Figure 2. Larval fitness curve (total body mass of adult insects emerged per seed) of two strains of S. zeamais, one susceptible and one resistant to insecticides, subjected to increasing density of eggs on maize seeds (and therefore increasing levels of larval competition). Each symbol represents the mean of observed results for each strain. $\bigcirc$ : Susceptible; $\nabla$ : resistant. Box plots (dark grey: susceptible; light grey: resistant) were superimposed on the regression lines indicating the range of data dispersion (lower and upper quartiles and extreme values), median, and outliers (symbols). The number of seeds at each egg density is indicated in italic on or within the box plots. Only (insect) body mass data from seeds with at least one emerging adult were considered. 
Lessells 1985; Giga \& Smith 1991; Guedes et al. 2007). In this study, digital X-ray image recording was also carried out throughout the larval development within each seed (and for every parasitized seed) to recognize the distribution and interaction of the larvae within the seed and therefore directly identify the behavioural process of competition taking place in them. The analysis of covariance for the number of encounters among larvae within the seed indicated a significant effect of egg density $\left(F_{5,120}=26.9\right.$; $P<0.001)$. There was no significant effect $(P>0.05)$ of strain nor of the interaction between strain and egg density. Therefore, the data of both strains were pooled together and a linear relationship was obtained between egg density and number of encounters between larvae within the seed (Fig. 3). The linear relationship indicates that the probability of the larvae interfering with one another increases as egg density increases. In addition, the number of larval interactions per seed was negatively correlated with relative adult emergence $(N=13 ; r=-0.76 ; P=0.002)$, suggesting that the larval encounter within the seed apparently leads to mortality of one of the interacting larvae. The representative (temporal) sequences of images shown in Figs. 4 and 5 illustrate the main results observed and are consistent with the results of larval interaction within the seed. The image sequence of the larva hatched from a single egg laid in the seed in Fig. 4a illustrates its behaviour. The eggs are usually laid near the seed germ, and the hatched larva burrows into the seed away from the germ and towards the endosperm. When larger numbers of eggs are laid in a single seed, as in Fig. $4 \mathrm{~b}$, the larvae hatched from these eggs located near the germ interfere with one another in the nearby region during early burrowing and while moving away from the germ. Only two larvae usually survive the initial interference from conspecifics and place themselves at the centre of the seed at opposite ends of the endosperm away from the germ, where they pupate and eventually emerge as adults.

The interference behaviour among larvae within a seed is more clearly shown in the sequences of images in Fig. 5. The first sequence of X-ray images shows the interaction between three hatched larvae (Fig. 5a). One of the three larvae $\left(L_{1}\right)$ approaches one

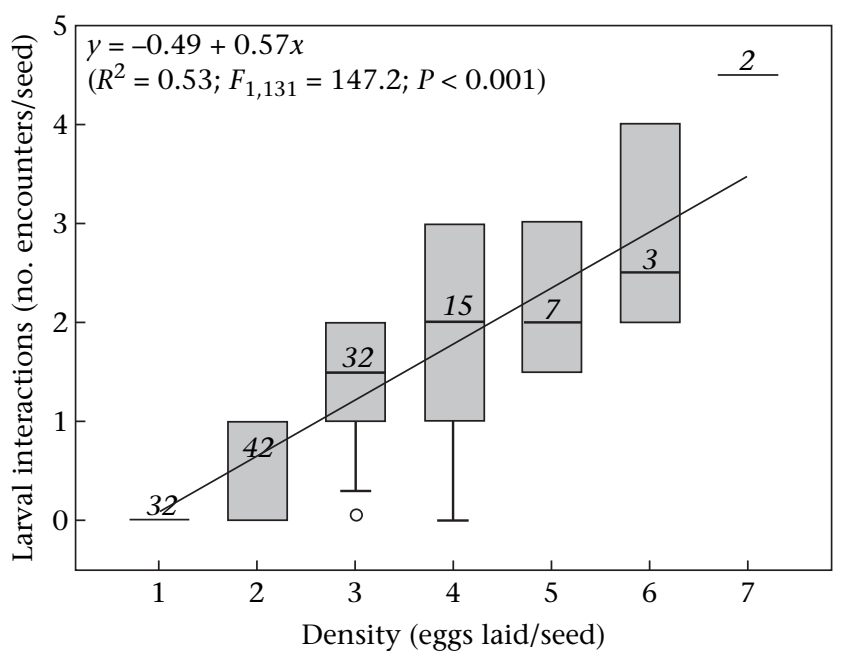

Figure 3. Larval interaction within seeds (number of larval encounters within the seed until adult emergence) of two strains of S. zeamais, one susceptible and one resistant to insecticides, subjected to increasing density of eggs on maize seeds (and therefore increasing levels of larval competition). Data for the two strains were pooled together to fit the linear model $y=\alpha+\beta x$. Box plots were superimposed on the regression lines indicating the range of data dispersion (lower and upper quartiles and extreme values), median, and outliers (symbols). The number of seeds at each egg density is indicated in italic on or within the box plots. Only data from seeds with at least one emerging adult were considered. of similar size $\left(\mathrm{L}_{3}\right)$, but their interaction does not take place, probably because of the coalescence of the burrows from $L_{1}$ and the smaller $\mathrm{L}_{2}$. The larger larva $\left(\mathrm{L}_{1}\right)$ seems to interfere with (or briefly attack) the smaller one $\left(\mathrm{L}_{2}\right)$ before pupating $\left(\mathrm{P}_{1}\right)$; the other larva $\left(\mathrm{L}_{3}\right)$ also pupates $\left(\mathrm{P}_{3}\right)$ without apparent damage. An even clearer interference and attack are illustrated in the image sequence of Fig. $5 b$, in which, of the three early competing larvae, one is soon eliminated $\left(\mathrm{L}_{3}\right)$ and one of the remaining two larvae burrows towards the other. They meet 24 days after egg-laying and the pursuing larva $\left(\mathrm{L}_{1}\right)$ kills and consumes its competitor, eventually emerging alone from the seed. The last sequence of images (Fig. $5 \mathrm{c}$ ) shows a coalescence of multiple larval burrows around the seed germ region in their initial development with only one larva surviving and moving to the centre of the seed. A smaller larva $\left(L_{3}\right)$, hatched from an egg laid in the opposite side of the seed, which shows delayed development, moves towards the extreme edge of the endosperm, avoiding interference by the large larva $\left(L_{1}\right)$, but then successfully pursues, attacks, and kills it upon its pupation. The images obtained provide evidence of active interference by means of aggression among conspecific larvae and cannibalism among them.

\section{DISCUSSION}

A contest-behavioural process of competition leading to a contest outcome was expected among maize weevil larvae based on the low adult emergence per parasitized seed reported for this species (Throne 1994; Danho et al. 2002; Danho \& Haubruge 2003a). Such pattern was expected to be even clearer in the insecticide-resistant strain of maize weevil because of its higher food consumption and respiration rates (as well as body mass). In contrast, the larval fitness curves suggested a scramble outcome of competition in both strains studied, but this conclusion was compromised because of the coincidently low optimum egg density observed (two eggs per seed in both strains). The absolute emergence rate from seeds indicated a contest outcome of competition, and X-ray imaging analysis of seeds provided evidence of contest-like competition with direct aggression among larvae within the seeds. Hence, one should be cautious in inferring the underlying type of competitive behaviour from variables such as body mass, adult emergence, and initial egg density per seed. Direct observation of behaviour is required to make such an inference.

Larval competition in granivorous species has important effects on the evolution of behaviour, and the behaviour has consequences for the rate of population growth and stability because there is density-dependent behavioural modulation of the larval interaction within a seed (Smith \& Lessells 1985). The consequences of scramble behaviour of larval competition on population dynamics have been studied in Drosophila by Jansen \& Sevenster (1997), who recognized that intraspecific competition regulates population size, leading to stable equilibrium when the larvae's growth rate is small compared to adult fecundity. Similar predictions would be expected in strains of maize weevil if their larvae showed scramble behaviour of larval competition.

Adults of internally feeding seed beetles lay eggs on or inside a seed selected by the mother, and the offspring are unable to leave this resource patch, leading to larval competition within the seed if multiple eggs are laid per seed. Some species of seed beetles minimize larval competition by laying few (or just one) eggs per seed in a uniform or random distribution, as observed in Callosobruchus species, which also tend to avoid parasitized seeds (e.g. Smith \& Lessells 1985; Messina 1991, 2004; Smith 1991). In contrast, egg distribution in weevils of the genus Sitophilus is generally regarded as clumped, particularly in the case of the maize 


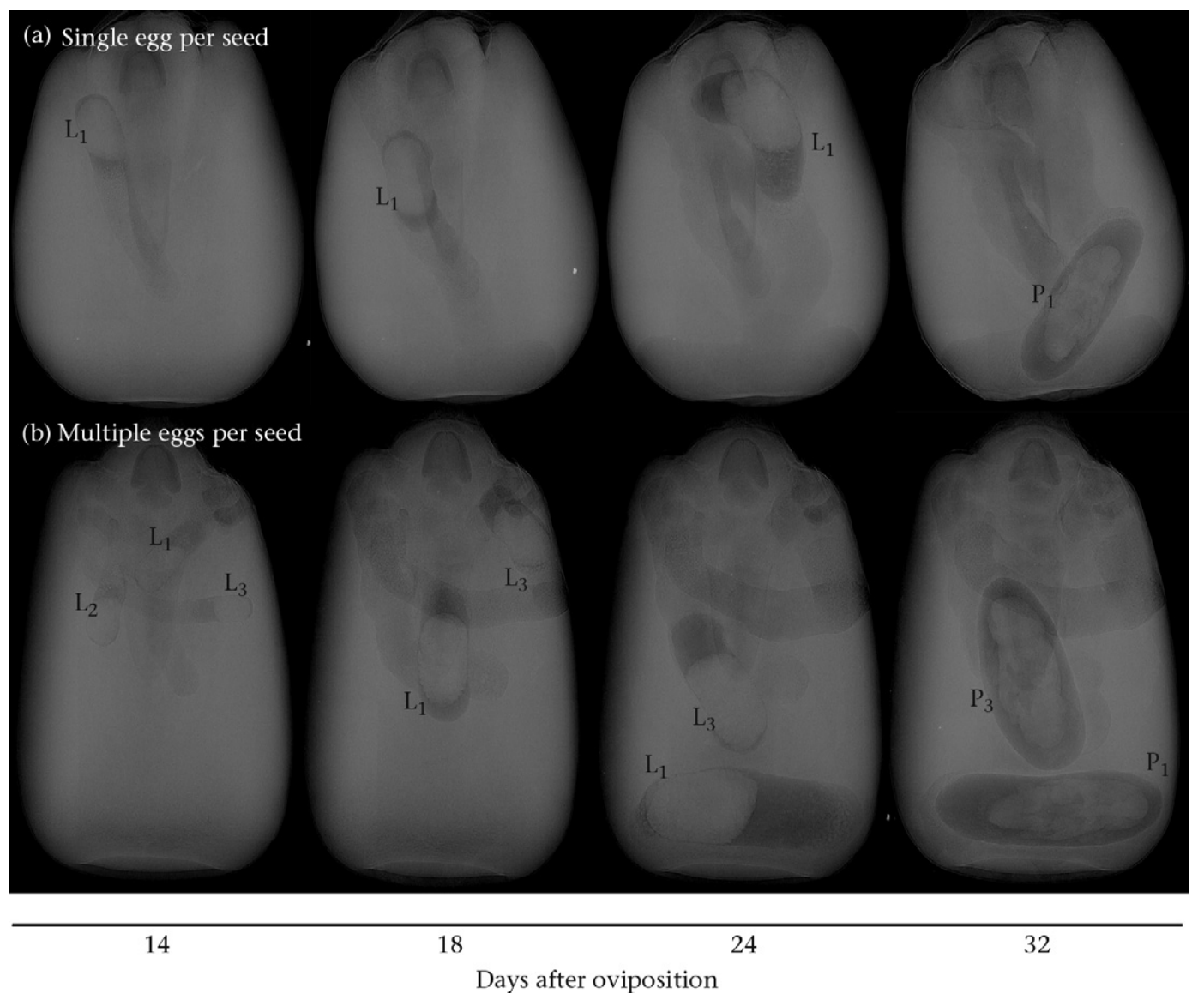

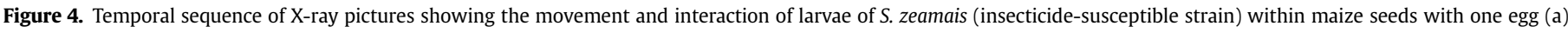

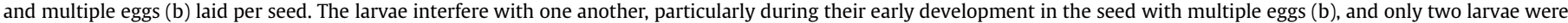
able to pupate and emerge as adults. The developmental stage (either larva or pupa) is indicated (L or P, respectively), as well as the individual larvae (1, 2, 3).

weevil (Dobie 1974; Legg et al. 1987; Nardon et al. 1988; Fava \& Burlando 1995; Stejskal \& Kučerová 1996; Danho \& Haubruge 2003a). Despite this seed superparasitism by the maize weevil, few individuals of this species emerge from seeds infested by much more than a few larvae (Throne 1994; Danho et al. 2002; Danho \& Haubruge 2003a). This is expected under intense competition and may take place with or without aggression among individuals within the seed.

Low adult emergence in internally feeding seed beetles can result from either scramble or contest competition depending on resource availability. Resource availability decreases as egg density increases, and the egg distribution of maize weevils indicates intense competition among larvae. Indeed, the intensity of competition determined in our study by the adult emergence curves as a function of egg density was equally strong for both strains. This similar intensity of competition took place regardless of the differences in respiration rate observed between the maize weevil strains, unlike in the cowpea weevil in which higher respiration rate usually leads to more intense competition (Guedes et al. 2003, 2007).

The larval fitness curves or competition curves indicate the competition outcome of the strains of maize weevil. If a plateau is reached in the larval fitness curve at higher densities, contest competition takes place, which, although less frequent among insect species (Price 1975; Mano et al. 2007), was reported in a few species such as some strains of Callosobruchus analis and C. maculatus and Ravena rubiginosa (Curculionidae) (Toquenaga \& Fujii 1990; Alves-Costa \& Knogge 2005; Guedes et al. 2007). In contrast, both strains of maize weevil showed humped larval fitness curves with optimal egg density at two eggs per seed indicating scramble outcome of competition with a low optimal egg density. Such optimal egg density for the maize weevil came as a surprise given the clumped egg distribution reported for females of this species (Dobie 1974; Legg et al. 1987; Nardon et al. 1988; Fava \& Burlando 1995; Stejskal \& Kučerová 1996; Danho \& Haubruge 2003a). However, these studies were based on laboratory experiments, and the high egg densities observed, together with their pattern of distribution, may be the result of confining the females with limited numbers of seed kernels. In fact, egg aggregation decreases with egg density and increases with female density (Legg et al. 1987; Danho et al. 2002), and field studies and laboratory investigations circumventing such conditions indicate a prevalence of around two eggs per seed in Sitophilus spp. (Pedersen 1979; Stubbs \& Abood 1983; Throne 1994; Campbell 2002; Niewiada et al. 2005). These results are in accordance with the optimal egg density reported here for $S$. zeamais. The sex ratio of the maize weevil is usually not affected by environmental conditions (Throne 1994), as also observed in this study. We also did not detect significant variation in developmental time of this species.

The scramble outcome of competition with low optimum egg density (two eggs per seed) observed for both strains of maize weevil may result from either a scramble behavioural process of larval competition with a low optimum egg density or a contestbehavioural process of competition with direct interference among the larvae. There was no reduction in body mass with increased 


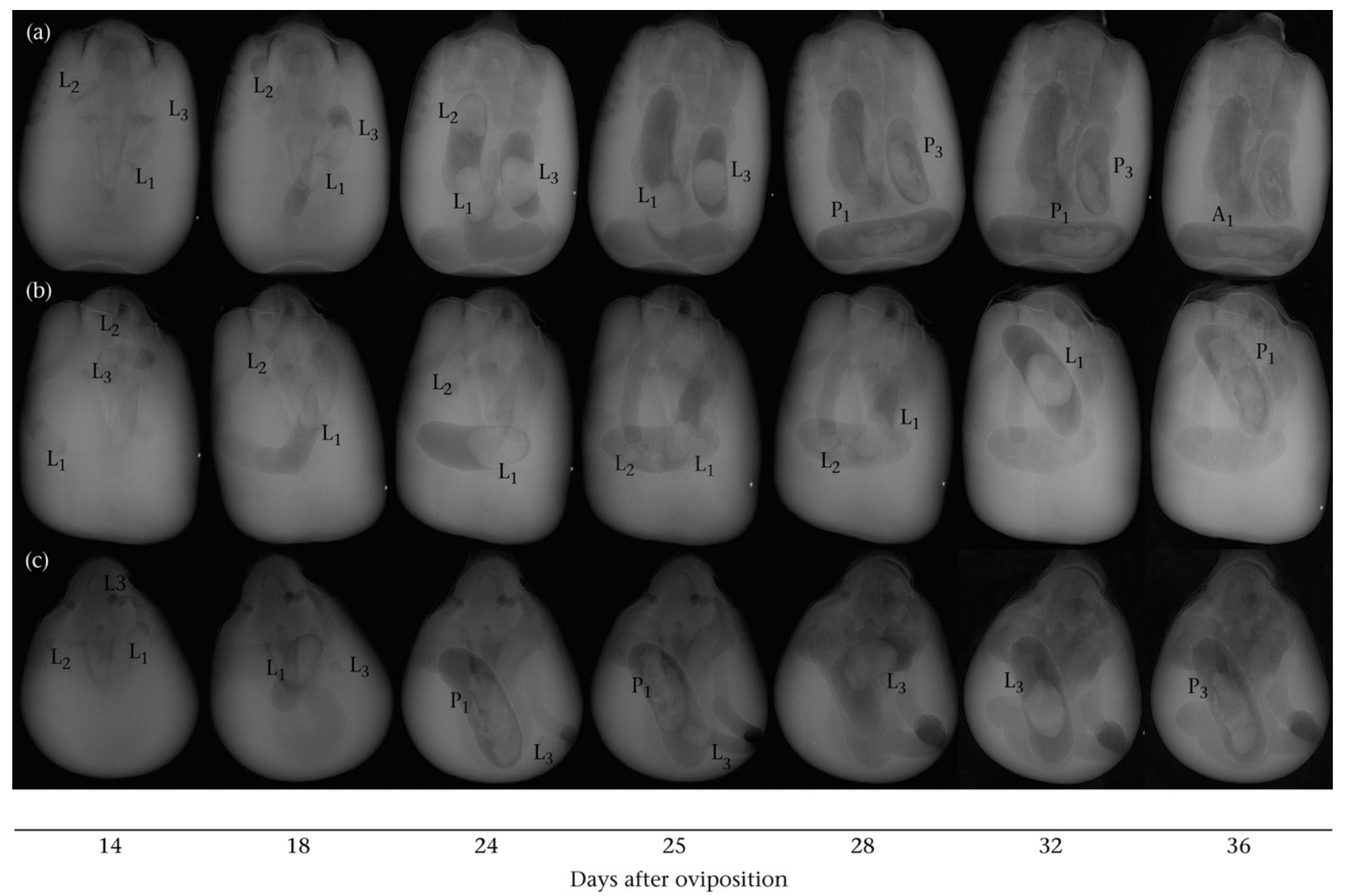

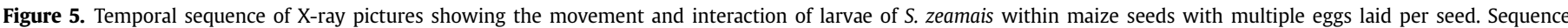

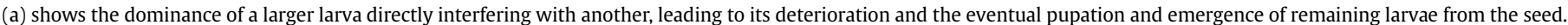

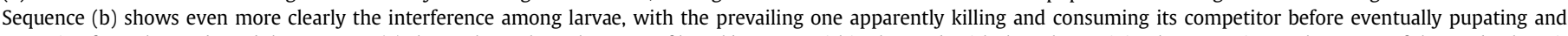

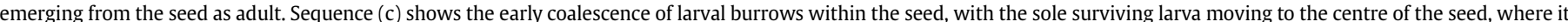

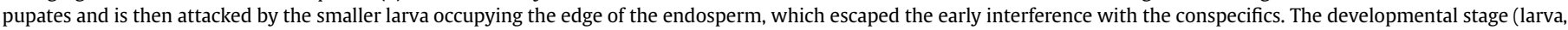
pupa, or adult) is indicated (L, P, and A, respectively), as well as the individual larvae $(1,2,3)$.

competition in either strain of maize weevil, but the low optimal egg density observed (two eggs per seed) indicates that body mass is unlikely to be reduced in the emerging adults, compromising the conclusion of a contest type of behavioural process based on this trait. Seed size may potentially affect both the optimal egg density observed in this study and the relationship between egg density and variation in body mass (Smith 1990; Fox et al. 1996; Messina 2004). Seed size differences affecting the relationship between egg density and variation in body mass were not considered in this investigation, but some indirect evidence for that has been reported in Sitophilus (Campbell 2002). Regardless of this, the combined results of low optimal egg density and no body mass reduction with increasing larval density indicate that body mass is unlikely to be reduced in the emerging adults, compromising the conclusion of a contest type of behavioural process based on this trait. However, X-ray images of the larvae within the seeds throughout their development indicate direct interference, with aggression taking place among them in a contest-behavioural process of competition. Therefore the consequences of scramble behaviour of larval competition for population dynamics recognized in Drosophila by Jansen \& Sevenster (1997) may not be applicable for the maize weevil. However, variability arising from larval development and from parental genetic variation seem important for the population dynamics of not only scramble competitors (e.g. Drosophila), but also contest competitors such as the maize weevil.
The contest-behavioural process of larval competition in the maize weevil is probably adaptive especially under seed superparasitism. At low egg densities, no interference behaviour is likely to take place between the larvae, which will have enough resources for their development and reproduction. In contrast, at high egg densities (i.e. seed superparasitism), interference behaviour with aggression in the case of the maize weevil will take place among the larvae, with the survival of one individual per seed. Such competition between larvae may confer indirect and direct benefits to the maize weevil. The potential indirect benefits of the seed superparasitism are the increase in genetic diversity (i.e. reflected in greater fitness differences) among competing individuals and in the number of individual larvae competing within the seed, potentially increasing offspring fitness. In addition to these indirect benefits, the cannibalism among larvae also evidenced in this study may enhance the survival of the cannibalistic larva, compensating for reproductive costs and ultimately increasing individual fitness (Danho et al. 2002). This hypothesis is supported by the fact that the quality of survivors does not seem compromised by competition, and a peak in larval fitness was reached for two eggs laid per seed, suggesting that the insect surviving the competition may indeed be fitter. Danho \& Haubruge (2003a) went so far as to suggest, based on preliminary evidence, that females emerging from seeds superparasitized by the maize weevil were more fecund because of the food acquired from cannibalism than females emerging from seeds carrying a single egg. This suggestion is 
supported by evidence from the red flour beetle, Tribolium castaneum (Tenebrionidae) (Ho \& Dawson 1966; Stevens 1989). Such potential benefits of seed superparasitism associated with the contest process of larval competition in seed beetles deserve future attention to understand the simultaneous evolution of both traits.

\section{Acknowledgments}

We thank the Minas Gerais State Foundation for Research Aid, the Brazilian National Council of Scientific and Technological Development, the CAPES Foundation of the Brazilian Ministry of Education, and the USDA-GMPRC for financial and structural support. The comments and suggestions provided by Drs. K.Y. Zhu, A. Janssen, and S.L. Elliot and Professor M.W. Sabelis on an early draft of the manuscript were greatly appreciated. The technical assistance provided by A. Redmon was also appreciated. Mention of trade names or commercial products in this publication is solely for the purpose of providing specific information and does not imply recommendation or endorsement by the Federal University of Viçosa or the U.S. Department of Agriculture.

\section{References}

Alves-Costa, C. \& Knogge, C. 2005. Larval competition in weevils Revena rubiginosa (Coleoptera: Curculionidae) preying on seeds of the palm Syagrus romanzoffiana (Arecaceae). Naturwissenschaften, 92, 265-268.

Anderson, M. 1978. Natural selection of offspring numbers: some possible intergeneration effects. American Naturalist, 112, 762-766.

Araújo, R. A., Guedes, R. N. C., Oliveira, M. G. A. \& Ferreira, G. H. 2008. Enhanced activity of carbohydrate- and lipid-metabolizing enzymes in insecticide-resistant populations of the maize weevil, Sitophilus zeamais. Bulletin of Entomological Research, 98, 417-424.

Bakker, K. 1961. An analysis of factors which determine success in competition for food among larvae of Drosophila melanogaster. Archives Néerlandaises de Zöologie, 2, 250-281.

Bellows, T. S. 1982. Analytical models for laboratory populations of Callosobruchus chinensis and Callosobruchus maculatus (Coleoptera: Bruchidae). Journal of Animal Ecology, 51, 263-287.

Campbell, J. F. 2002. Influence of seed size on exploitation by the rice weevil, Sitophilus oryzae. Journal of Insect Behavior, 15, 429-445.

Colegrave, N. 1994. Game theory models of competition in closed systems: asymmetries in fighting and competitive ability. Oikos, 71, 499-505.

Colegrave, N. 1997. Can a patchy population structure affect the evolution of competition strategies? Evolution, 51, 483-492.

Credland, P. F. \& Dick, K. M. 1987. Food consumption by larvae of three strains of Callosobruchus maculatus (F.) (Coleoptera: Bruchidae). Journal of Stored Products Research, 23, 31-40.

Credland, P. F., Dick, K. M. \& Wright, A. W. 1986. Relationships between larval density, adult size and egg production in cowpea seed beetle, Callosobruchus maculatus. Ecological Entomology, 11, 41-50.

Danho, M. \& Haubruge, E. 2003a. Optimal clutch size and oviposition strategy for the maize weevil, Sitophilus zeamais. In: Advances in Stored Product Protection (Ed. by P. F. Credland, D. M. Armitage, C. H. Bell, P. M. Cogan \& E. Highley), pp. 59-64. Wallingford: CAB International.

Danho, M. \& Haubruge, E. 2003b. Comportement de ponte et stratégie reproductive de Sitophilus zeamais (Coleoptera: Curculionidae). Phytoprotection, 84, 59-67.

Danho, M., Gaspar, C. \& Haubruge, E. 2002. The impact of grain quantity on the biology of Sitophilus zeamais Motschulsky (Coleoptera: Curculionidae): oviposition, distribution of eggs, adult emergence, body weight and sex ratio. Journal of Stored Products Research, 38, 259-266.

Daniel, S. H. \& Smith, R. H. 1994. Functional anatomy of the egg pore in Callosobruchus maculatus: a trade-off between gas-exchange and protective functions? Physiological Entomology, 19, 30-38.

De Jong, G. 1976. A model of competition for food. I. Frequency-dependent viabilities. American Naturalist, 110, 1013-1027.

Dobie, P. 1974. The laboratory assessment of the inherent susceptibility of maize varieties to post-harvest infestation by Sitophilus zeamais Motsch. (Coleoptera: Curculionidae). Journal of Stored Products Research, 10, 183-187.

Ellers, J., Van Alphen, J. J. M. \& Sevenster, J. G. 1998. A field study of size-fitness relationships in the parasitoid Asobara tabida. Journal of Animal Ecology, 67, 318-324.

Fava, A. \& Burlando, B. 1995. Influence of female age and grain availability on the ovipositional pattern of the wheat weevil Sitophilus granarius (Coleoptera: Curculionidae). European Journal of Entomology, 92, 421-426.

Fox, C. W., Martin, J. D., Thakar, M. S. \& Mousseau, T. A. 1996. Clutch size manipulations in two seed beetles: consequences for progeny fitness. Oecologia, 108, 88-94.
Fragoso, D. B., Guedes, R. N. C. \& Rezende, S. T. 2003. Glutathione S-transferase detoxification as a potential pyrethroid resistance mechanism in the maize weevil, Sitophilus zeamais. Entomologia Experimentalis et Applicata, 109, 21-29.

Fragoso, D. B., Guedes, R. N. C. \& Peternelli, L. A. 2005. Developmental rates and population growth of insecticide-resistant and susceptible populations of Sitophilus zeamais. Journal of Stored Products Research, 41, 271-281.

Giga, D. P. \& Smith, R. H. 1991. Intraspecific competition in the bean weevils Callosobruchus maculatus and Callosobruchus rhodesianus (Coleoptera: Bruchidae). Journal of Applied Ecology, 28, 918-929.

Guedes, R. N. C., Lima, J. O. G., Santos, J. P. \& Cruz, C. D. 1994. Inheritance of deltamethrin resistance in a Brasilian strain of maize weevil (Sitophilus zeamais Mots.). International Journal of Pest Management, 40, 103-106.

Guedes, R. N. C., Lima, J. O. G., Santos, J. P. \& Cruz, C. D. 1995. Resistance to DDT and pyrethroids in Brazilian populations of Sitophilus zeamais Motsch. (Coleoptera: Curculionidae). Journal of Stored Products Research, 31, 145-150.

Guedes, R. N. C., Kambhampati, S. \& Dover, B. A. 1997. Allozyme variation among Brazilian and U.S. populations of Rhyzopertha dominica resistant to insecticides. Entomologia Experimentalis et Applicata, 84, 49-57.

Guedes, R. N. C., Smith, R. H. \& Guedes, N. M. P. 2003. Host suitability, respiration rate and the outcome of larval competition in strains of the cowpea weevil, Callosobruchus maculatus. Physiological Entomology, 28, 298-305.

Guedes, R. N. C., Oliveira, E. E., Guedes, N. M. P., Ribeiro, B. \& Serrão, J. E. 2006 Cost and mitigation of insecticide resistance in maize weevil, Sitophilus zeamais. Physiological Entomology, 31, 30-38.

Guedes, R. N. C., Guedes, N. M. P. \& Smith, R. H. 2007. Larval competition within seeds: from the behaviour process to the ecological outcome in the seed beetle Callosobruchus maculatus. Austral Ecology, 32, 697-707.

Guedes, N. M. P., Guedes, R. N. C., Ferreira, G. H. \& Silva, L. B. 2009a. Flight take-off and walking behaviour of insecticide-susceptible and -resistant strains of Sitophilus zeamais exposed to deltamethrin. Bulletin of Entomological Research, 99, 393-400.

Guedes, N. M. P., Guedes, R. N. C., Silva, L. B. \& Cordeiro, E. M. G. 2009b. Deltamethrin-induced feeding plasticity in pyrethroid-susceptible and -resistan strains of the maize weevil, Sitophilus zeamais. Journal of Applied Entomology, 133, 524-532.

Ho, F. K. \& Dawson, P. S. 1966. Egg cannibalism by Tribolium larvae. Ecology, 47 318-322.

Horn, S.-B. 1997. Larval competition and egg-laying decisions by the bean weevil Callosobruchus maculatus. Animal Behaviour, 53, 1-12.

Jansen, V. A. A. \& Sevenster, J. G. 1997. An individual-based model for competing Drosophila populations. Researches on Population Ecology, 39, 215-225.

Kazmer, D. J. \& Luck, R. F. 1995. Field tests of the size-fitness hypothesis in the egg parasitoid Trichogramma pretiosum. Ecology, 76, 412-425.

Lale, N. E. S. \& Vidal, S. 2001. Intraspecific and interspecific competition in $\mathrm{Cal}$ losobruchus maculatus (F.) and Callosobruchus subinnotatus (Pic) on stored bambara groundnut, Vigna subterranea (L.) Verdcourt. Journal of Stored Products Research, 37, 329-338.

Legg, D. E., Barney, R. J., Tipping, P. W. \& Rodriguez, J. G. 1987. Factors influencing the distribution of maize weevil (Coleoptera: Curculionidae) eggs on maize. Environmental Entomology, 16, 809-813.

Lomnicki, A. 1988. Population Ecology of Individuals. Princeton, New Jersey: Princeton University.

Mano, H. \& Toquenaga, Y. 2008a. Wall-making behaviour in Callosobruchus maculatus (Coleoptera: Bruchidae). Annals of the Entomological Society of America 101, 449-455.

Mano, H. \& Toquenaga, Y. 2008b. Wall-making behaviour as a proximate mechanism to generate variation in larval competition in Callosobruchus maculatus (Coleoptera: Bruchidae). Evolutionary Ecology, 22, 177-191.

Mano, H., Toquenaga, Y. \& Fujii, K. 2007. Scramble-like contest competition in Callosobruchus analis (Coleoptera: Bruchidae). Journal of Stored Products Research, 43, 211-220.

Messina, F. J. 1991. Life-history variation in a seed beetle: adult egg-laying vs. larval competition ability. Oecologia, 85, 447-455.

Messina, F. J. 2004. Predictable modification of body size and competitive ability following a host shift by a seed beetle. Evolution, 58, 2788-2797.

Miller, R. S. 1967. Pattern and process of competition. Advances in Ecological Research, 4, 1-74

Nardon, P., Grenier, A. M. \& Chessel, D. 1988. Comportement de ponte de la femelle de Sitophilus oryzae L. (Coleoptera: Curculionidae): problème du choix dês grains et du site de ponte sur le grain. Bulletin de la Société Entomologique de France, 106, 487-495.

Nicholson, A. J. 1954. An outline of the dynamics of animal populations. Australian Journal of Zoology, 2, 9-65.

Niewiada, A., Nawrot, J., Szafranek, J., Szafranek, B., Synak, E., Jelén, H. \& Wasowicz, E. 2005. Some factors affecting egg-laying of the granary weevil (Sitophilus granarius L.). Journal of Stored Products Research, 41, 544-555.

Nylin, S. 2001. Life history perspectives on pest insects: what's the use? Austral Ecology, 26, 507-517.

Oliveira, E. E., Guedes, R. N. C., Tótola, M. R. \& Marco, P. D. 2007. Competition between insecticide-susceptible and -resistant populations of the maize weevil, Sitophilus zeamais. Chemosphere, 69, 17-24.

Pedersen, J. R. 1979. Selection of oviposition sites on wheat kernels by Sitophilus spp.: effect of moisture, temperature and kernel size. Ph.D. thesis, Kansas State University, Manhattan. 
Price, P. W. 1975. Insect Ecology. New York: J. Wiley.

Reddy, D. B. 1951. Determination of sex in adult rice and granary weevils (Coleoptera: Curculionidae). Pan-Pacific Entomologist, 27, 13-16.

Ribeiro, B. M., Guedes, R. N. C., Oliveira, E. E. \& Santos, J. P. 2003. Insecticide resistance and synergism in Brazilian populations of Sitophilus zeamais (Coleoptera: Curculionidae). Journal of Stored Products Research, 39, 21-31.

Sanz, M. J. \& Gurrea, P. 2000. Life-cycles and competition-avoiding strategies of seed-eating weevil species on broom species (Coleoptera: Curculionidae/ Leguminosae: Genisteae). Entomologia Generalis, 24, 237-254.

SAS Institute 2002. SAS/STAT User's Guide. Version 8. Cary, North Carolina: SAS Institute.

Smith, R. H. 1990. Adaptations of Callosobruchus species to competition. In: Bruchids and Legumes: Economics, Ecology and Coevolution (Ed. by K. Fujii, A. M. R. Gatehouse C. D. Johnson, R. Mitchell \&Y. Yoshida), pp. 351-360. Dordrecht: Kluwer Academic.

Smith, R. H. 1991. Genetic and phenotypic aspects of life-history evolution in animals. Advances in Ecological Research, 21, 63-120.

Smith, R. H. \& Lessells, C. M. 1985. Oviposition, ovicide and larval competition in granivorous insects. In: Behavioural Ecology: Ecological Consequences of Adap tative Behaviour (Ed. by R. M. Sibly \& R. H. Smith), pp. 423-448. London: Blackwell Scientific.

SPSS 2000. TableCurve 2D User's Guide. Chicago: SPSS.

Stejskal, V. \& Kučerová, Z. 1996. The effect of grain size on the biology of Sitophilus granarius L. (Col., Curculionidae). I. Oviposition, distribution of eggs and adult emergence. Journal of Applied Entomology, 120, 143-146.

Stevens, L. 1989. The genetics and evolution of cannibalism in flour beetles (genus Tribolium). Evolution, 43, 169-179.
Stubbs, M. \& Abood, F. 1983. Oviposition by Sitophilus granarius (L.) (Coleoptera: Curculionidae) in insect contaminated wheat. Journal of Stored Products Research, 19, 51-56.

Tanaka, Y. 1990. Age specificity of inbreeding depression during a life cycle of Callosobruchus chinensis (Coleoptera: Bruchidae). Researches on Population Ecology, 32, 329-335.

Thanthianga, C. \& Mitchell, R. 1987. Vibrations mediate prudent resource exploitation by competing larvae of the bruchid bean weevil Callosobruchus maculatus. Entomologia Experimentalis et Applicata, 44, 15-21.

Throne, J. E. 1994. Life history of immature maize weevils (Coleoptera: Curculionidae) on corn stored at constant temperatures and relative humidities in the laboratory. Environmental Entomology, 23, 1459-1471.

Tolpo, N. C. \& Morrison, E. O. 1965. Sex determination by snout characteristics of Sitophilus zeamais Motschulsky. Texas Journal of Science, 17, 122-124.

Toquenaga, Y. 1993. Contest and scramble competitions in Callosobruchus maculatus (Coleoptera: Bruchidae). II. Larval competition and interference mechanisms. Researches on Population Ecology, 35, 57-68.

Toquenaga, Y. \& Fujii, K. 1990. Contest and scramble competitions in two bruchid species, Callosobruchus analis and C. phaseoli (Coleoptera: Bruchidae). I. Larva competition curves and interference mechanisms. Researches on Population Ecology, 32, 349-363.

Tran, B. M. D. \& Credland, P. F. 1995. Consequences of inbreeding for the cowpea seed beetle, Callosobruchus maculatus (F.) (Coleoptera: Bruchidae). Biological Journal of the Linnean Society, 56, 483-503.

Varley, G. C., Gradwell, G. R. \& Hassell, M. P. 1973. Insect Population Ecology. Oxford: Blackwell. 